Bull. Mater. Sci., Vol. 6, No. 1, February 1984, pp. 65-70.

(C) Printed in India.

\title{
Dependence of microstructure on process variables in manganese zinc ferrites
}

\author{
N VENKATARAMANI, R AIYAR*, P S SEKHAR** and \\ C M SRIVASTAVA*
}

Advanced Centre for Research in Electronics, *Department of Physics, ** Materials Science Centre, Indian Institute of Technology, Bombay 400076, India

\begin{abstract}
The dependence of microstructure on sintering conditions during hot pressing have been investigated and the densification mechanisms have been used to explain the observed results. The effect of addition of excess $\mathrm{ZnO}$ content over stoichiometry on permeability has been studied in the normal sintered $\mathrm{Mn}-\mathrm{Zn}$ ferrites.
\end{abstract}

Keywords. Hot pressing; manganese zinc ferrites; densification mechanism; sintering.

\section{Introduction}

The initial permeability of manganese zinc ferrites is a sensitive function of the microstructure. To achieve high permeability the microstructure has to be controlled. In hot pressed ferrites this can be controlled by the sintering conditions (temperature and pressure) employed in a modified technique developed earlier (Venkataramani et al 1982). In normal sintered ferrites the evaporation of $\mathrm{Zn}$ during sintering alters the stoichiometry and affects the microstructure and permeability. Thus excess $\mathrm{ZnO}$ must be taken to offset this loss due to evaporation. Here we discuss the effect of varying this excess $\mathrm{ZnO}$ over stoichiometric content from 0 to $10 \%$ on the microstructure.

\section{Experimental procedure}

\subsection{Hot pressing}

The composition chosen for this study was $53 \mathrm{~mol} \% \mathrm{Fe}_{2} \mathrm{O}_{3}, 27 \mathrm{~mol} \% \mathrm{MnO}$ and $20 \mathrm{~mol} \% \mathrm{ZnO}$. The powders were processed by the usual ceramic technique. During hot pressing the presintered compact was initially soaked at a lower temperature $\left(1100^{\circ} \mathrm{C}\right)$ under pressure $(\sim 20 \mathrm{MPa})$ and subsequently the temperature was increased to the final temperature $\left(1200^{\circ} \mathrm{C}\right)$ maintaining the temperature constant, for various sintering times shown in table 1 . This was followed by the ejection of the sample at the final temperature and the sintered pellet was cooled in $\mathrm{N}_{2}$ atmosphere. For comparison we have prepared another pellet by directly heating to $1275^{\circ} \mathrm{C}$ (without soak) and cooling within the die. To evaluate the mechanism involved during the final stages of sintering, the time of sintering was varied from 0 to $4 \mathrm{hr}$ at the final temperature.

\subsection{Normal sintering}

From the phase diagram for permeability by Roess (1970) the starting composition was chosen as $53 \mathrm{~mol} \% \mathrm{Fe}_{2} \mathrm{O}_{3}, 23 \mathrm{~mol} \% \mathrm{MnO}$ and $24 \mathrm{~mol} \% \mathrm{ZnO}$. The firing schedule and 
Table 1. Densification rates of hot pressed $\mathrm{Mn}-\mathrm{Zn}$ ferrites

\begin{tabular}{|c|c|c|c|c|c|c|c|}
\hline \multirow[b]{2}{*}{$\begin{array}{l}\text { Sintering } \\
\text { time } \\
(\mathrm{hr})\end{array}$} & \multirow[b]{2}{*}{$\begin{array}{l}\text { Observed } \\
\text { density } \\
\left(\mathrm{kgm}^{-3}\right)\end{array}$} & \multirow[b]{2}{*}{$\begin{array}{c}\text { o of } \\
\text { theoretical } \\
\text { density }\end{array}$} & \multicolumn{3}{|c|}{ Calculated strain rates for } & \multirow[b]{2}{*}{$\begin{array}{l}\text { Total densi- } \\
\text { fication rate } \\
10^{4} \mathrm{~kg} \mathrm{~m}^{-3} \mathrm{sec}^{-1}\end{array}$} & \multirow[b]{2}{*}{$\begin{array}{l}\text { Calculated } \\
\% \text { density }\end{array}$} \\
\hline & & & $\begin{array}{l}\text { Nabarro } \\
\text { Herring } \\
10^{-3} \sec ^{-1}\end{array}$ & $\begin{array}{c}\text { Coble } \\
10^{3} \sec ^{-1}\end{array}$ & $\begin{array}{c}\text { Bird } \\
\text { et al } \\
10^{4} \sec ^{-1}\end{array}$ & & \\
\hline 0.5 & 4990 & $97 \cdot 27$ & 5.68 & $4 \cdot 27$ & $2 \cdot 36$ & 72.0 & $98 \cdot 21$ \\
\hline 1.0 & 5090 & $99 \cdot 22$ & 5.68 & $4 \cdot 27$ & $2 \cdot 36$ & $61 \cdot 7$ & 98.98 \\
\hline $2 \cdot 0$ & 5093 & $99 \cdot 28$ & $3 \cdot 20$ & 1.80 & $2 \cdot 36$ & 11.9 & $99 \cdot 46$ \\
\hline $3 \cdot 0$ & 5108 & 99.57 & 1.80 & $7 \cdot 60$ & $2 \cdot 36$ & $10 \cdot 3$ & $99 \cdot 66$ \\
\hline $4 \cdot 0$ & 5119 & $99 \cdot 79$ & 1.50 & 3.89 & $2 \cdot 36$ & $4 \cdot 7$ & 99.79 \\
\hline
\end{tabular}

ambient were adjusted to yield good density and single phase. The sintering schedule finally adopted was as follows: $1275^{\circ} \mathrm{C}$ in $\mathrm{N}_{2}+1 \% \mathrm{O}_{2}$ for $3 \mathrm{hr}$ followed by $1350^{\circ} \mathrm{C}$ in $\mathrm{N}_{2}+1 \% \mathrm{O}_{2}$ for 4 hours and cooled in pure $\mathrm{N}_{2}$ to room temperature. Atomic absorption spectroscopy and wet chemical analysis on several samples showed the final composition to be $\mathrm{Zn}$ deficient up to $6 \mathrm{wt} \% \mathrm{ZnO}$. Hence different samples were prepared with varying $\mathrm{ZnO}$ excess, progressively increasing from 0 to $10 \%$, keeping the same sintering schedule as above. The results are discussed in \$3.2.

\section{Discussion}

In this investigation the aim was to study the rate of densification using the hot pressing method by varying the duration of the final sintering. The change in microstructure was also studied. Normal sintering was used to study the effect of zinc loss on microstructure and permeability.

\subsection{Densification mechanism in hot pressing}

There are three significant processes which have been reported to occur during the final stages of hot pressing (Wilkinson and Ashby 1975; Notis et al 1975). These are (i) vacancy motion through the bulk lattice along a stress-induced gradient (NabarroHerring model) (ii) stress directed diffusional flow along the grain boundaries (Coble model) and (iii) deformation accompanied by climb and glide of dislocations (Bird et al model). These mechanisms have been used to compute the strain rate $(\dot{\varepsilon})$ using the equations given in Notis et al (1975). These in turn were used to calculate the total densification rate using

$$
\dot{\rho}=\dot{\varepsilon}(3 / 2)^{n+1}(g / n)^{n} \frac{(1-\rho)}{\left[1-(1-\rho)^{1 / n}\right]^{n}},
$$

where $n$ is the effective stress exponent obtained from our data, $g$ the stress correction $(\sim 1)$ when $\rho$, the relative density is close to 1 . The results of this calculation are given in table 1 . In figure 1 we plot the density as a function of sintering time at the final temperature. The observed and calculated values show good agreement.

From table 1 it is clear that the Nabarro-Herring type strain rate is the predominant densification mechanism. This process also leads to higher grain boundary mobilities resulting in enhanced grain growth. It has also been observed that the soak at $1100^{\circ} \mathrm{C}$ 


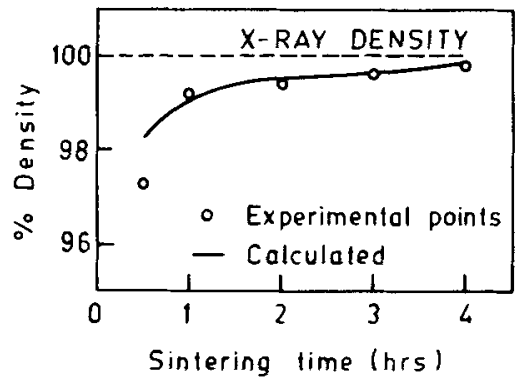

Figure 1. Densification characteristics of hot pressed $\mathrm{Mn}-\mathrm{Zn}$ ferrites.

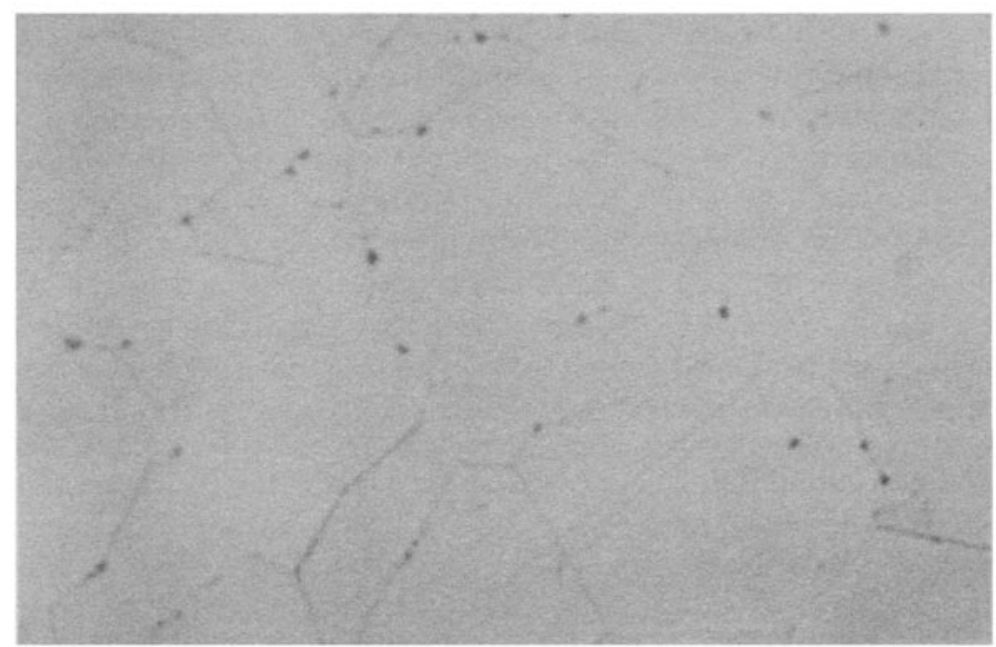

(a)

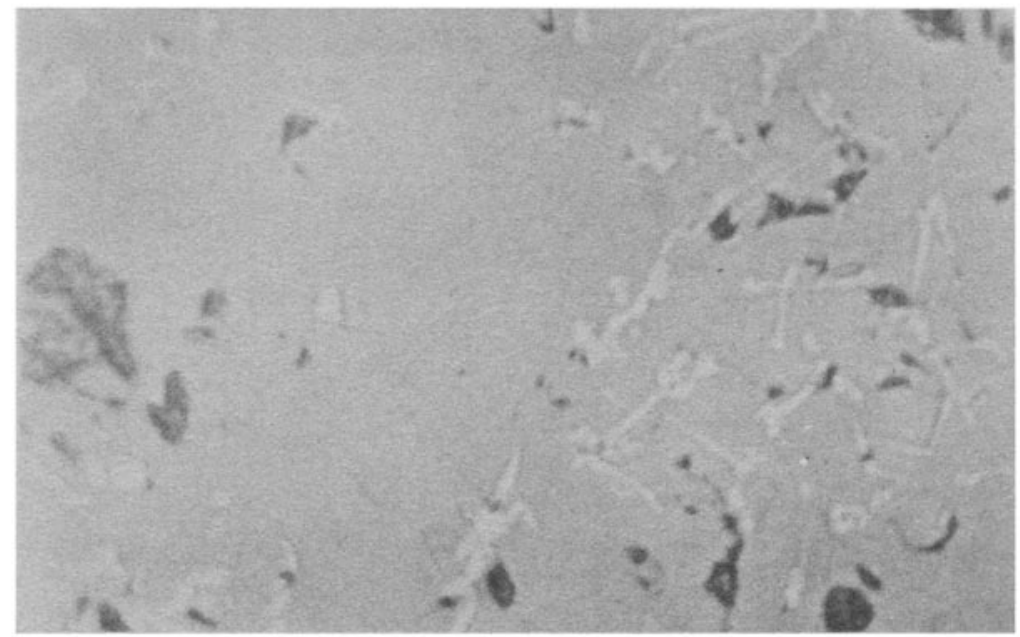

(b)

Figure 2. Microstructure photographs of $\mathrm{Mn}-\mathrm{Zn}$ ferrites (a) hot pressed at $1100^{\circ} \mathrm{C}$ for $2 \mathrm{hr}$, $1250^{\circ} \mathrm{C}$ for $3 \mathrm{hr}$, hot ejected and cooled in $\mathrm{N}_{2}$ (b) hot pressed at $1275^{\circ} \mathrm{C}$ for $2.5 \mathrm{hr}$ and cooled within the die. $(1 \mathrm{~cm}=15 \mu \mathrm{m})$ 
gives higher densities without appreciable grain growth. The energy supplied at $1200^{\circ} \mathrm{C}$ after the soak period leads to only grain growth since the separation of the densification process and grain growth is seen in this sintering schedule.

Using such an approach we have prepared a large grain $\mathrm{Mn}-\mathrm{Zn}$ ferrite $(\sim 30-40 \mu \mathrm{m})$ with useful properties for recording head applications. The permeability is between 4000 and 5000 . In contrast a sample sintered at $1275^{\circ} \mathrm{C}$ without soaking at $1100^{\circ} \mathrm{C}$ and without hot ejection resulted in a grain size of $10 \mu \mathrm{m}$ and a density of $5050 \mathrm{~kg} \mathrm{~m}^{-3}$. These differences are evident from figure 2 which shows the microstructure photographs of these two samples. The second phase precipitation in figure $2(b)$ is due to cooling within the die.

\subsection{Normal sintered ferrites}

We have observed that as the excess $\mathrm{ZnO}$ concentration increases from 0 to $4.5 \%$ the initial permeability increases and the microstructure gets refined, becoming more homogeneous. Thereafter the microstructure worsens again leading to discontinuous grain growth which also lowers the permeability. Figure 3 shows the variation of $\mu_{i}$ with excess $\mathrm{ZnO}$ concentration and figure 4 shows the microstructures of $2 \mathrm{wt} \%, 4 \mathrm{wt} \%$ and $5 \mathrm{wt} \%$ excess, $\mathrm{ZnO}$ compositions. From these results we see that the optimum composition is close to $4 \%$ excess $\mathrm{ZnO}$. This composition has a density of $4850 \mathrm{~kg} \mathrm{~m}^{-3}$ and an average grain size of $12 \mu \mathrm{m}$. On varying the composition in smaller steps in this range the best composition was found to be $4.2 \mathrm{wt} \%$ excess $\mathrm{ZnO}$. This composition was prepared and found to have a homogeneous microstructure with minimal pores (figure $5)$ and an initial permeability $\sim 4000$.

\section{Conclusions}

In hot-pressed manganese zinc ferrites control of grain size with good density can be obtained by soaking at a lower temperature, a suitable choice of the final sintering temperature and hot ejection. To achieve high permeability in normal sintered ferrites

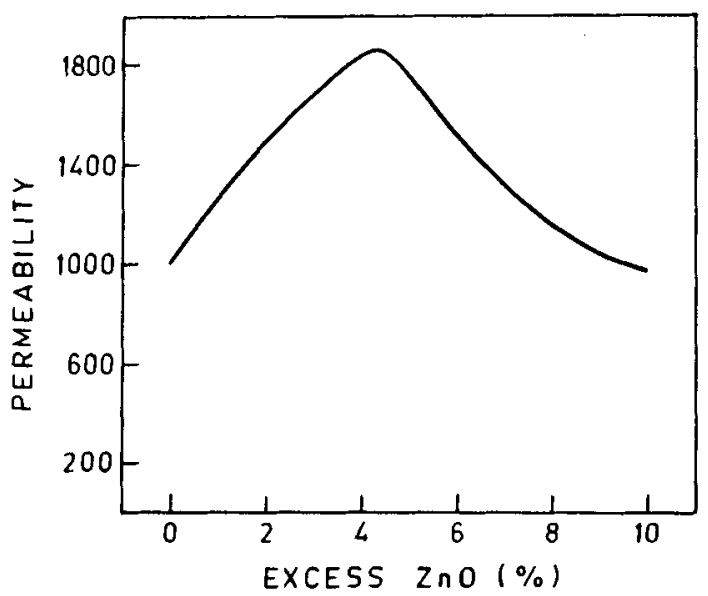

Figure 3. Permeability as a function of excess $\mathrm{ZnO}$ in normal sintered $\mathrm{Mn}-\mathrm{Zn}$ ferrites. 


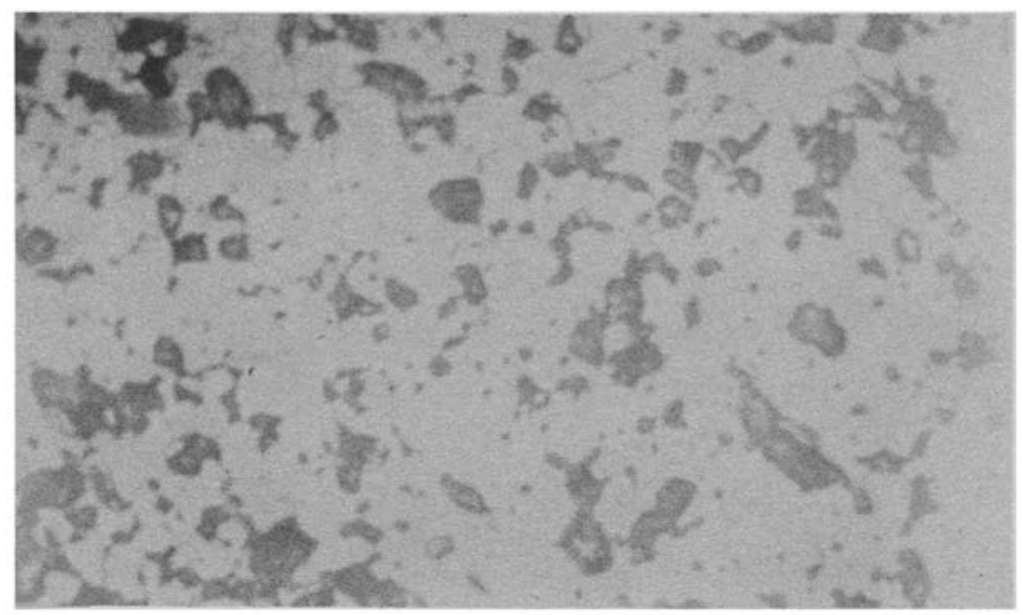

(a)

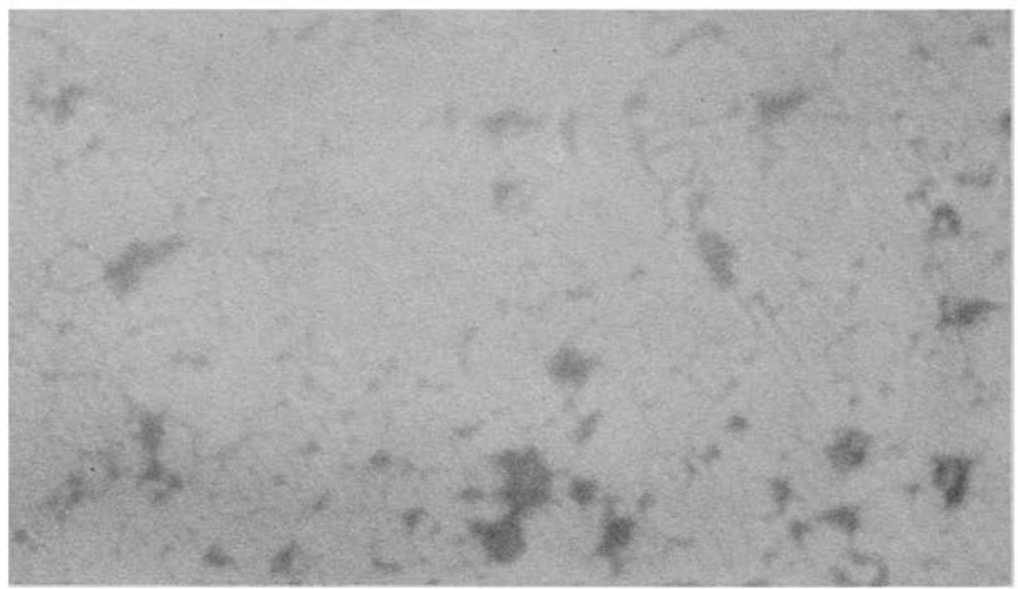

(b)

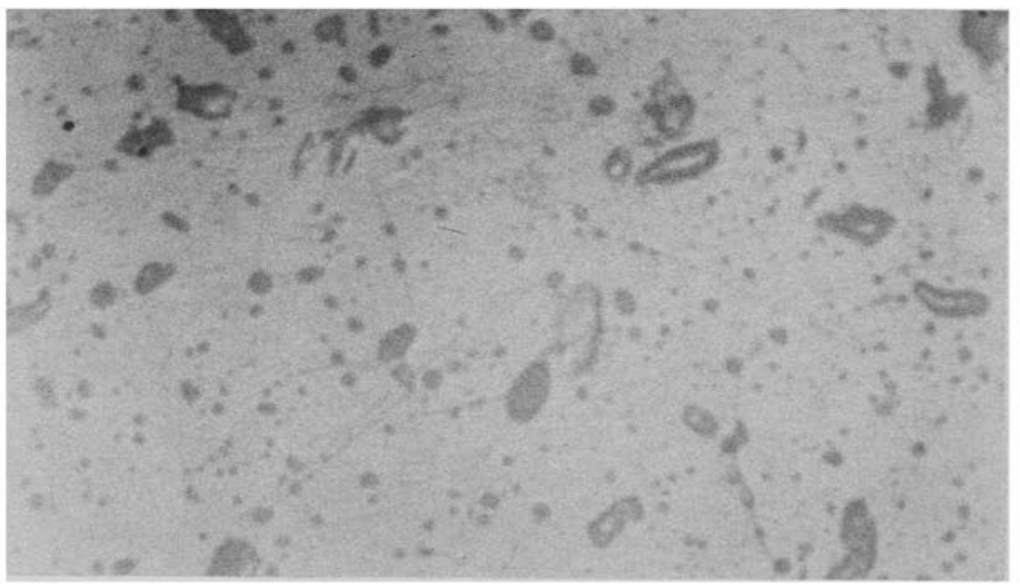

(c)

Figure 4. Microstructure photographs of (a) $2 \mathrm{wt} \%$ (b) $4 \mathrm{wt} \%$ and (c) $5 \mathrm{wt} \%$ excess $\mathrm{ZnO}$ compositions. $(1 \mathrm{~cm}=30 \mu \mathrm{m})$ 


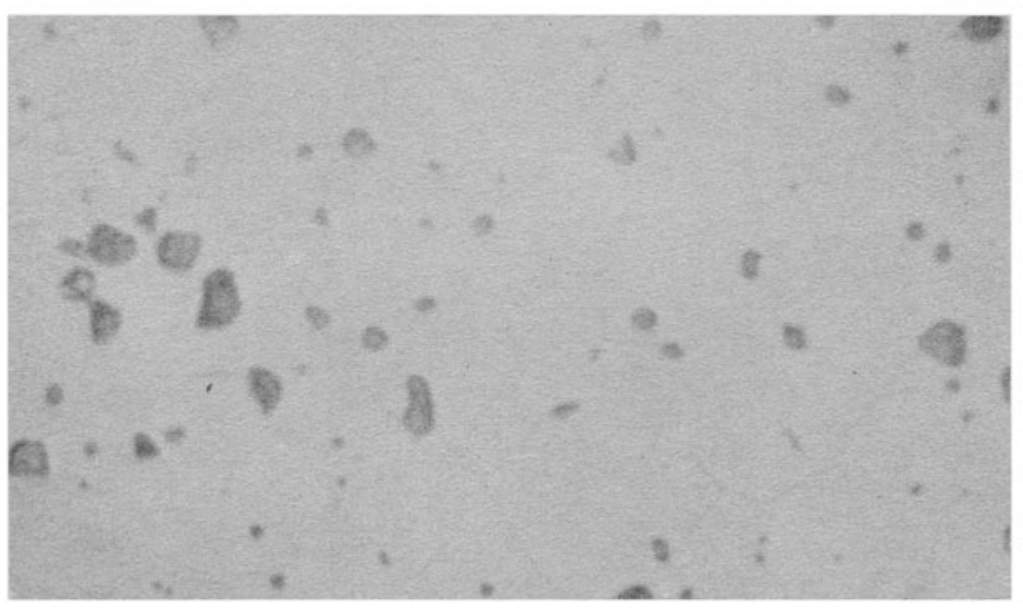

Figure 5. Microstructure photograph of $4.2 \mathrm{wt} \%$ excess composition. $(1 \mathrm{~cm}=15 \mu \mathrm{m})$

using the sintering schedule discussed here an optimum excess of $4.2 \mathrm{wt} \% \mathrm{ZnO}$ over the stoichiometry is necessary.

\section{Acknowledgement}

The authors are grateful to the Department of Science and Technology for financing this study.

\section{References}

Notis M R, Smoak R M and Krishnamachari V 1975 Materials science research (ed.) G C Kuczynski (New York: Plenum) Vol. 10, p. 493

Roess E 1970 Ferrites, Proc. Int. Conf. (eds.) Y Hoshino and S Iida (Tokyo: University of Tokyo Press) p. 203 Venkataramani N, Aiyar R, Sekar P S and Srivastava C M 1982 Ceramics, Proc. Int. Symposium (Bangalore: BHEL) p. 6.12

Wilkinson D S and Ashby M F 1975 Materials science research (ed.) G C Kuzynski (New York: Plenum) Vol. 10, p. 473 